\title{
VIBRATION CONTROL FOR PRECISION MANUFACTURING USING PIEZOELECTRIC ACTUATORS
}

\author{
David R. Martinez ${ }^{1}$, Terry D. Hinnerichs ${ }^{2}$ and James M. Redmond ${ }^{3}$
}

\section{Structural Dynamics and Vibration Control Department}

\author{
Sandia National Laboratories
}

Albuquerque, NM

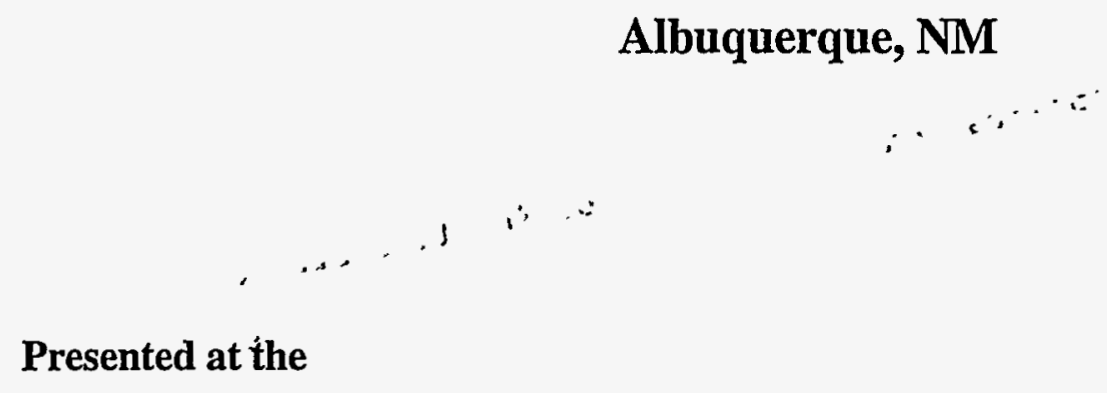

Sixth International Conference on Adaptive Structures

Key West, Florida

November 13-15, 1995

DISCLAIMER

This report was prepared as an account of work sponsored by an agency of the United States Government. Neither the United States Government nor any agency thereof, nor any of their employces, makes any warranty, express or implied, or assumes any legal liability or responsibility for the accuracy, completeness, or usefulness of any information, apparatus, product, or process disclosed, or represents that its use would not infringe privately owned rights. Reference herein to any specific commercial product, process, or service by trade name, trademark, manufacturer, or otherwise does not necessarily constitute or imply its endorsement, recommendation, or favoring by the United States Government or any agency thereof. The views and opinions of authors expressed herein do not necessarily state or reflect those of the United States Government or any agency thereof. 


\begin{abstract}
Piezoelectric actuators provide high frequency, force, and stiffness capabilities along with reasonable stroke limits, all of which can be used to increase performance levels in precision manufacturing systems. This paper describes two examples of embedding piezoelectric actuators in structural components for vibration control. One example involves suppressing the self excited chatter phenomenon in the metal cutting process of a milling machine and the other involves damping vibrations induced by rigid body stepping of a photolithography platen. Finite element modeling and analyses are essential for locating and sizing the actuators and permit further simulation studies of the response of the dynamic system. Experimental results are given for embedding piezoelectric actuators in a cantilevered bar configuration, which was used as a surrogate machine tool structure. These results are incorporated into a previously developed milling process simulation and the effect of the control on the cutting process stability diagram is quantified. Experimental results are also given for embedding three piezoelectric actuators in a surrogate photolithography platen to suppress vibrations. These results demonstrate the potential benefit that can be realized by applying advances from the field of adaptive structures to problems in precision manufacturing.
\end{abstract}

\title{
INTRODUCTION
}

One of the accuracy limiting characteristics of precision manufacturing equipment is vibration. The rigid body process control system or the self-excited regenerative phenomena within a manufacturing process are two causes of these vibrations. Rapid rigid body stepping in the photolithography process results in increasing through-put for semiconductor chips but it also can excite one or more flexible modes of the moving structure (Redmond et al., 1994) causing precision difficulties. Similarly, an example of a regenerative phenomenon is the socalled chatter (Jemielniak and Widota, 1989; Smith and Tlusty, 1987, 1988, 1991; Tlusty and Ismail, 1983; Smith and Delio, 1992; Manufacturing Laboratories, Inc., 1993; Redmond, 1994), that can develop between the tool and the workpiece of a milling machine. Chatter is the intermittent separation of the tool from the workpiece while cutting due to the interaction of cutting forces that change with time and the dynamic stiffness of the milling machine. Clearly, both of these vibration occurrences reduce quality and can even result in hardware failures. This

\footnotetext{
${ }^{1}$ David R. Martinez, Manager, Structural Dynamics and Vibration Control Dept.,Sandia National Laboratories, MS0439, Albuquerque, NM 87185, USA. Email: drmarti@ sandia.gov

${ }^{2}$ Terry D. Hinnerichs, Senior Mechanical Engineer, Structural Dynamics and Vibration Control Dept., Sandia National Laboratories, MS0439, Albuquerque, NM 87185, USA. Email: tdhinne@sandia.gov

${ }_{3}$ James M. Redmond, Senior Member of the Technical Staff, Structural Dynamics and Vibration Control Dept., Sandia National Laboratories, MS0439, Albuquerque, NM 87185, USA. Email: jmredmo@sandia.gov
} 
paper discusses procedures for implementing control systems that use embedded piezoelectric actuators to reduce vibration amplitudes. The first two sections of this paper describe finite element modeling and analysis procedures for developing a chatter control system on a milling machine. The third section shows results of implementing an embedded set of piezoelectric actuators on a machine-like structure in the form of a cantilevered bar and presents the implied metal cutting stability improvements. The last two sections follow a similar approach of finite element modeling, control simulation and hardware experiments for embedded piezoelectric actuators in a surrogate photolithography platen.

\section{FINITE ELEMENT MODELING OF A SPINDLE AND TOOL ASSEMBLY}

A finite element model of a tool and milling machine spindle assembly, shown in Figure 1, was constructed to aid in the development of an active vibration control system (Dohner, 1995). The purpose of this control system was to increase cutting stability of a milling machine that has a long slender tool and thereby suppress the onset of tool chatter. The tool, tool holder and spindle were modeled as three cylinders with the dimensions given in Figure 1. All three components were modeled as being composed of steel.

The spindle is attached to the rest of the machine through a bearing located at each of its ends. Each bearing was modeled using a set of stiff springs. For the top bearing, 24 springs provided tensile and compressive support in the $\mathrm{x}, \mathrm{y}$ and $\mathrm{z}$ directions. Each of these 24 groups of three orthogonal springs were evenly spaced in the circumference with a spring constant of $1.0 \cdot 10^{6} \mathrm{lb}_{f} / \mathrm{in}$. The bottom bearing consisted of two springs in the y-direction and two springs in the z-direction as shown in Figure 1. Each of these springs had a stiffness of $6.0 \cdot 10^{6} l b_{f} /$ in stiffness.

\section{MODAL ANALYSIS}

A simulated modal analysis of the tool and the spindle was performed using the finite element model described above for two configurations. In the first configuration, the stiff springs at the lower bearing location were included in the model. This configuration is representative of a very stiff machine tool design. Figure 2 shows the mode shapes of the first four modes that contribute to tool tip motion. The contours show areas of constant total displacements; white represents zero displacement. Notice that the $1280 \mathrm{~Hz}$ mode is a local tool mode which causes no motion at the lower bearing location and thus would be difficult to control with an active control system utilizing actuators attached to the spindle for tool tip displacement control purposes. Consider that an actuator installed on the tool holder just below the spindle bearing could theoretically apply loads to control bending, but the toolholder is rotating with the tool and this rotation, of course, causes additional complexities with power and sensor measurements. In a later section, it will be shown how well an embedded actuator can work in a nonrotating cantilevered bar configuration. However, here we are focused on locating actuators and sensors at the lower spindle bearing to control tool tip motion.

In the second configuration, the stiff springs at the lower bearing location were eliminated from the problem in an attempt to make the resulting vibration modes more observable and controllable at the lower bearing location. Figure 3 shows the mode shapes of the first four modes that contribute to tool tip motion for this second configuration. Again, total displacements are shown by contours. All of these modes produce some motion in the spindle. Therefore, to a relative degree, each mode can be sensed in the spindle and controlled there 


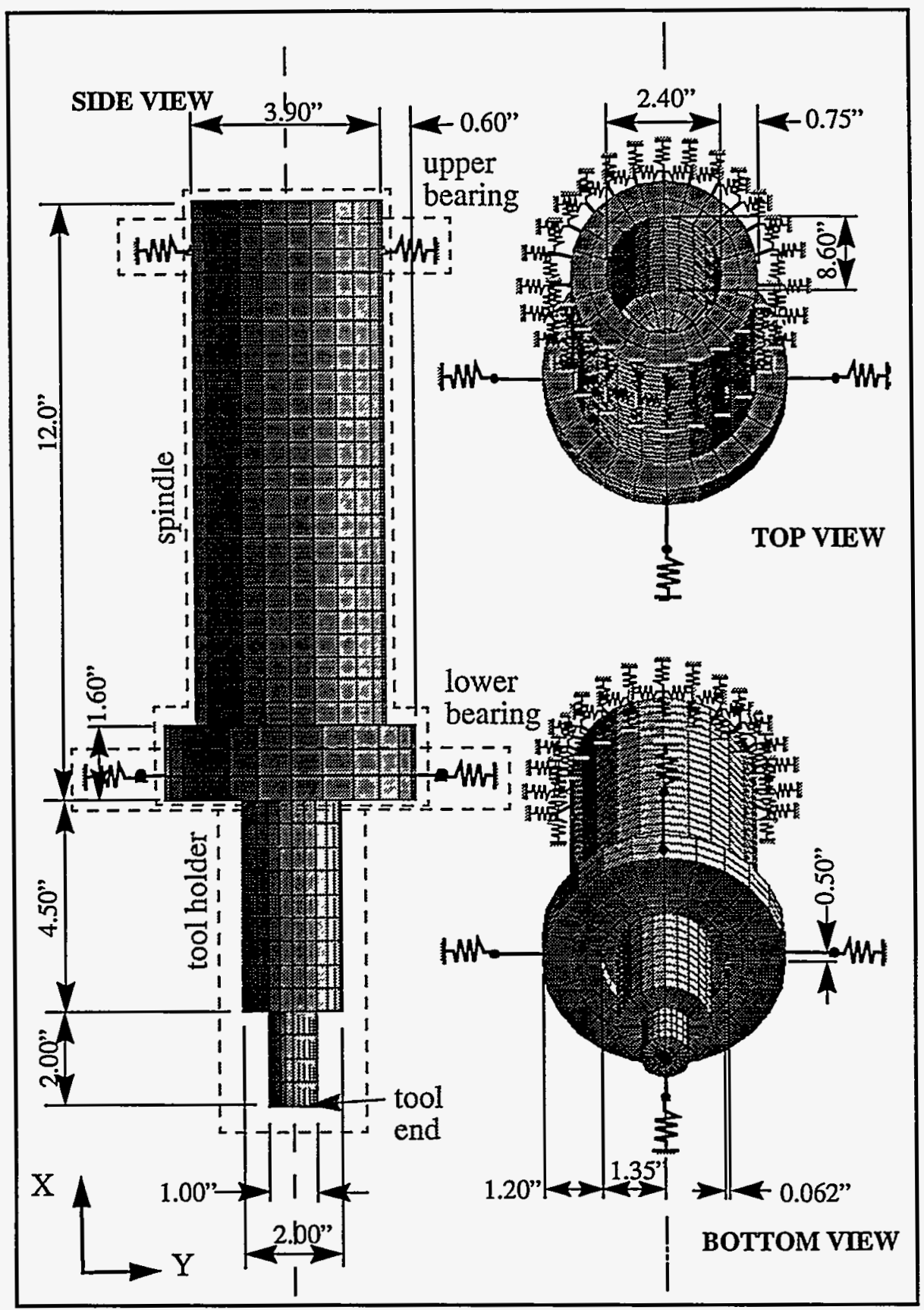

Figure (1): Finite element model of spindle and tool.

when the lower bearing stiffness is reduced. The control strategy currently being explored is to replace the stiff supporting springs at the lower bearing supports with piezoelectric actuators having lower static stiffness then the first configuration. These actuators could then be driven in a manner that increases dynamic stiffness at critical tool mode frequencies and with a resulting increase in cutting stability over passive stiff bearing supports. The design of a control system to minimize tool tip deflection can then be attempted by extracting a truncated modal model from this finite element model or obtaining an experimentally derived model from hardware system identification tests and incorporating this control strategy into a toolworkpiece interaction model (i.e. milling simulation). The first approximation for the truncated 


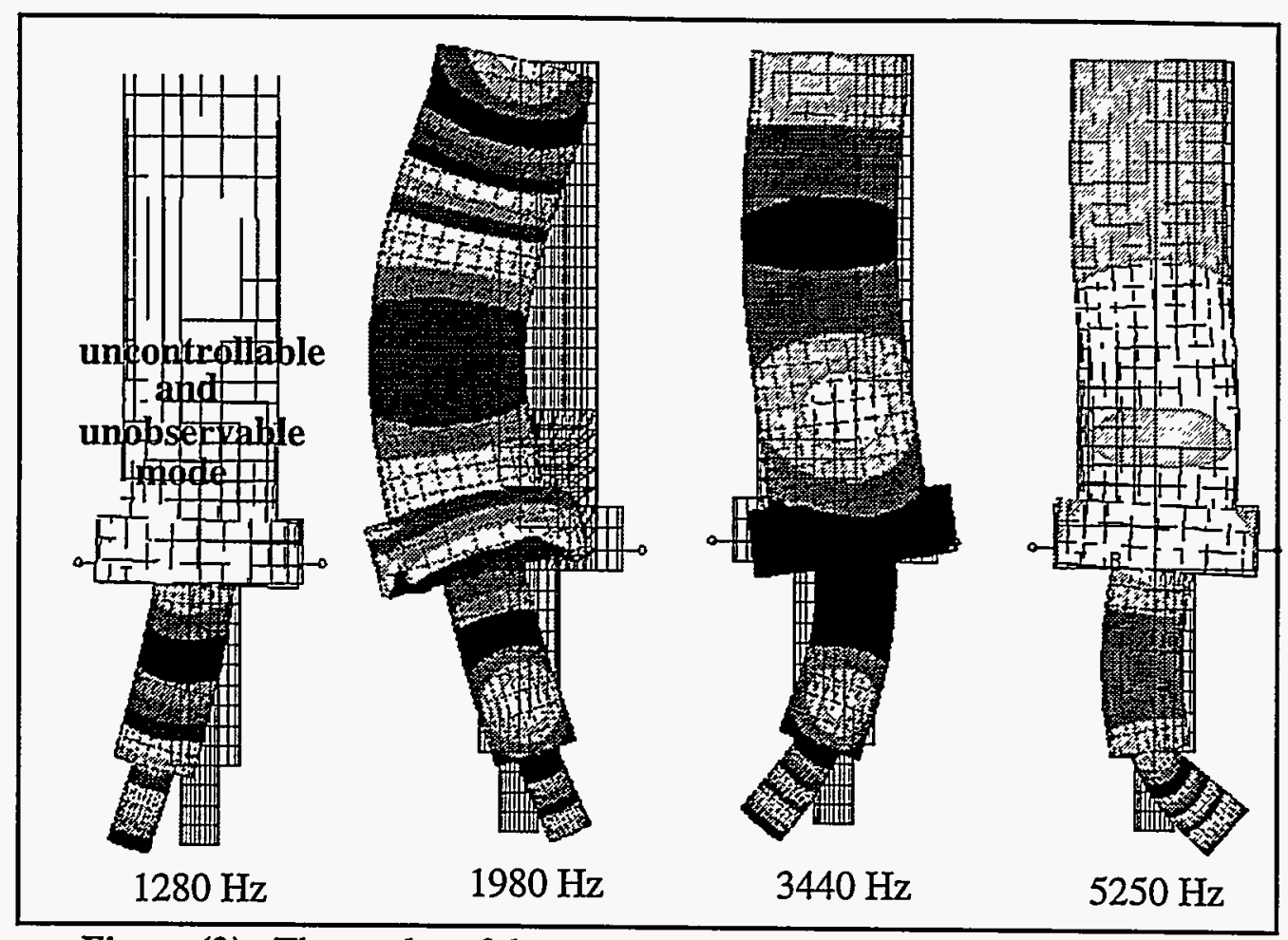

Figure (2): The modes of the system with a stiff spindle bearing support.

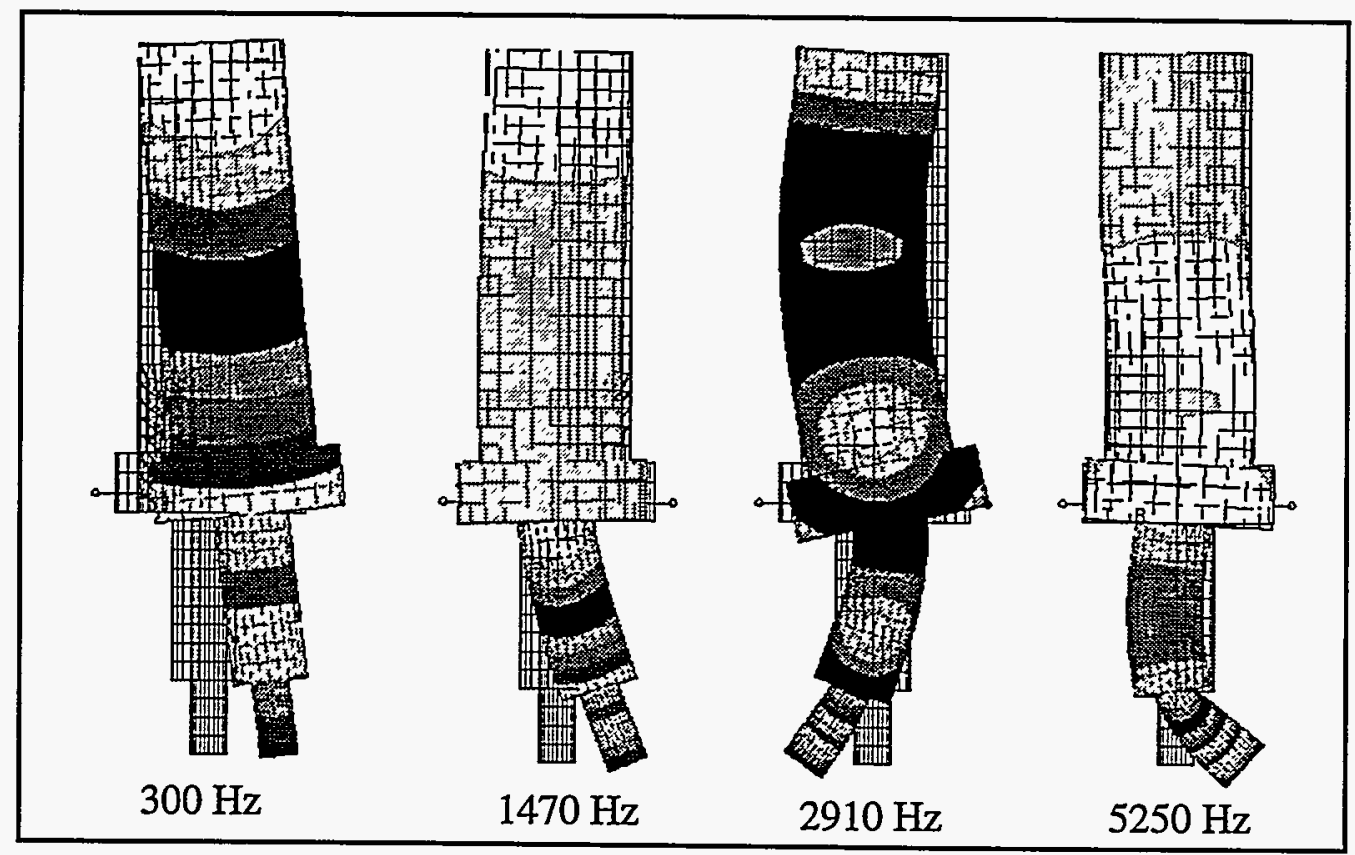

Figure (3): The modes of the system for a free condition at the lower bearing. model should include the four modes as shown in Figure 3. The next section discusses the milling simulation.

\section{MILING PROCESS SIMULATION}

The process of metal removal in milling couples the machine tool dynamics with the tangential and normal cutting forces generated at the tool-workpiece interface. Figure 4 shows 


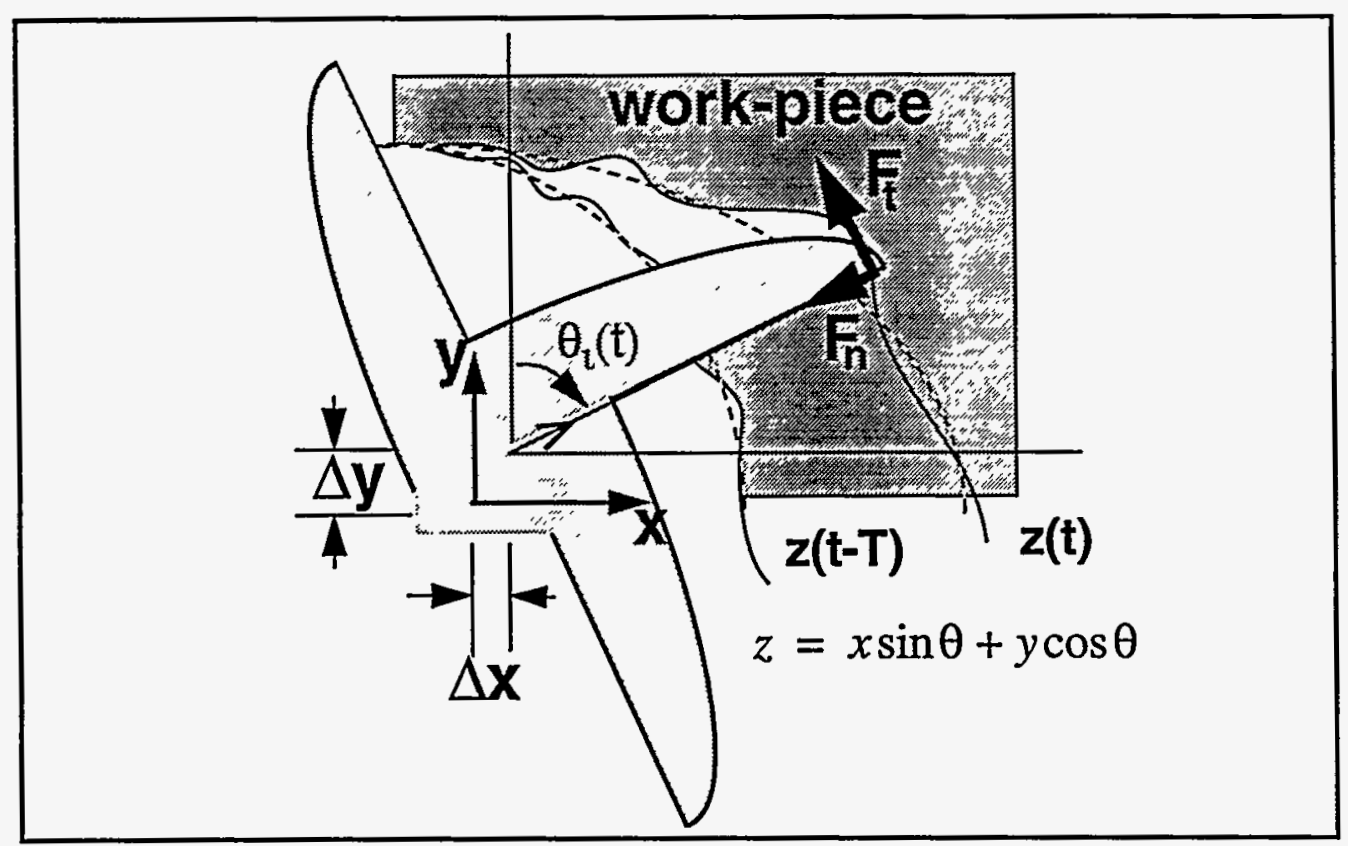

Figure (4): The regeneration of waviness.

a diagram of a milling tool passing through a workpiece. Ignoring the axial flexibility of the cutting tool, vibration of the cutting tool occurs in the X-Y plane.

In most cases, the dynamics of the cutting tool are dominated by the cutting tool/spindle assembly and this is why the finite element model in the first section of this paper focused only on the spindle/tool assembly. Although the $\mathrm{X}$ and $\mathrm{Y}$ dynamics may be slightly different due to the asymmetry of the tool structure, the free vibration of the cutting tool in inertial coordinates can be described using non rotating coordinates due to the assumed axial symmetry of the rotating spindle. Furthermore, since the spindle bearings are preloaded, the dynamics of the cutting assembly are consistent over a wide range of cutting speeds. Therefore, a model for the structure can be obtained by a linear finite element analysis of the spindle/tool assembly with appropriate supporting springs or boundary conditions. This model would then need to undergo significant order reduction to generate a low order state space model suitable for control design. Alternatively, driving point transfer functions containing all of the pertinent dynamics can be readily obtained experimentally by measuring the impulse response functions of the cutting tip. Then, a state space model of the form

$$
\begin{aligned}
& \underset{\dot{x}}{\dot{x}}(t)=A \underset{\sim}{x}(t)+B \underset{\sim}{f}(t) \\
& \underset{\sim}{\dot{y}}(t)=C \underset{\sim}{x}(t)+D \underset{\sim}{f}(t)
\end{aligned}
$$

can be generated using the Eigensystem Realization Algorithm (Juang and Pappa,1985; Dohner, 1994). In Equation 1 and Equation $2, A, B, C, D$ are the state space matrices, $\dot{x}(t)$ is the n dimensional state vector, $f(t)=\left[f_{x}(t) f_{y}(t)\right]^{T}$ is the input vector of cutting forces, and $y(t)=[X(t) Y(t)]^{T}$ is the vector of tip displacements along the $\mathrm{X}$ and $\mathrm{Y}$ axes. 
Several recent publications give models of the cutting process. Although the cutting force model is given in the literature (Smith and Tlusty, 1991; Manufacturing Laboratories, Inc.,1993), it is included here for completeness. Again, refer to the two dimensional drawing of the tool-workpiece interface in a half immersion up-milling configuration shown in Figure 4. This figure shows the non-rotating coordinate system which travels along the nominal tool path and is located at the center of the tool tip when the tool has zero deflection. As the tool rotates and traverses the workpiece, tangential and normal cutting forces are generated at each cutting insert located at angle $\theta_{\mathrm{i}}(\mathrm{t})$. Assuming straight cutting teeth (i.e. negligible helix angle), the tangential cutting force at the $\mathrm{i}^{\text {th }}$ cutting tooth can be approximated as

$$
F_{T i}(t)=K_{s} b h_{i}(t)
$$

where $K_{s}$ is the cutting stiffness of the workpiece, $b$ is the axial depth of cut, and $h_{i}(t)$ is the chip thickness. The normal component of the cutting force is less pronounced, but is generally approximated as

$$
F_{N i}(t)=0.3 F_{T i}(t)
$$

Due to the combined rotation and translation of the cutting tool, the nominal chip thickness varies as a tooth passes through the workpiece. Furthermore, the actual chip thickness is affected by the current and previous tool deflections since tool vibrations impose a waviness on the surface of the workpiece. Thus, the instantaneous chip thickness is given by

$$
h_{i}(t)=h_{i}(t)+z_{i}(t)-z_{i}(t-T)
$$

in which $\bar{h}_{i}(t)$ is the nominal chip thickness, $z_{i}(t)$ is the radial deflection of the tool tip, and $T$ is the time period between the pass of the current and the previous tooth. The nominal chip thickness is a function of the cutting parameters and the orientation of the cutting head given by

$$
\bar{h}_{i}(t)=\frac{f_{r}}{n m} \sin \theta_{i}(t)
$$

where $f_{r}$ is the feed rate, $n$ is the rotational speed of the cutting tool, and $m$ is the number of cutting teeth.

As shown in Equation 5, past vibrations of the cutting tip affect current vibrations by altering the instantaneous chip thickness and causing variations in the cutting forces. The effects of this regenerative forcing function depend largely on the phasing of current and previous vibrations. Note that for low cutting speeds, relatively small changes in the cutting speed can have a large effect on the phase angle between the current and the previous surface spatial oscillations. Conversely, at high speeds large variations in $n$ are needed to significantly alter the phasing of current and previous vibrations. This is the cause of the characteristic spreading out of stability lobes as speed increases.

For specific combinations of tool speed and axial depth of cut, the regenerative cutting force can cause vibrations of sufficient amplitude that the cutting tool intermittently loses contact with the workpiece, producing a characteristic chatter sound with each subsequent 
impact of the cutting tool against the workpiece. During the intervals of separation, the axial and normal cutting forces are zero and no new vibrational patterns are recorded on the surface of the workpiece. The cutting forces in the inertial frame are determined by summing the contributions from all cutting teeth according to

$$
\begin{aligned}
F_{x}(t) & \left.=\sum_{i=1}^{m}\left(-F_{T i}(t) \cos \theta_{i}(t)\right)-F_{N i}(t) \sin \theta_{i}(t)\right) \\
F_{y}(t) & =\sum_{i=1}^{m}\left(F_{T i}(t) \sin \theta_{i}(t)-F_{N i}(t) \cos \theta_{i}(t) .\right.
\end{aligned}
$$

Additional terms that affect the tool work-piece interaction include the process damping. This stabilizing term is related to the friction generated at the interface of the tool flank and the workpiece behind the cutting zone. Since this term is negligible at high cutting speeds, it has not been included in this simulation. Application and results from this simulation are discussed in the next section.

\section{BAR DAMPING EXPERIMENT}

In the metal removal by milling process, the cutting forces generated at the tool-workpiece interface excite bending modes of the tool and spindle. Such vibrations adversely affect workpiece surface finish and can lead to regenerative chatter vibrations. Although the high frequencies and small amplitude that are typical of tool vibrations make them difficult to target with active vibration control strategies, significant enhancements to machine tools could result from damping a single mode (Tarng and Li, 1994; Jemielniak and Widota, 1989), since the limiting depth of cut is usually defined by a single mode. In practice, the benefits are tempered by the existence of other modes of vibration. As the dynamic stiffness of the limiting mode is increased, the limiting depths of cut defined by other modes are likely to become more prominent. However, in many cases significant performance improvements can be achieved through modest increases in the damping of a single vibratory mode. This is the focus of the bar damping experiment discussed below (Redmond,1995).

For this experiment, a circular steel bar 30.5 centimeters long and 5.1 centimeters in diameter was cantilevered from a steel mounting plate as shown in Figure 5. Two piezoelectric actuators (lead zirconate titanate, PZT) aligned with the bar axis were mounted in material cutouts near the bar root. Nominally 5.1 centimeters long, 1.9 centimeters wide, and 1.9 centimeters deep, the rectangular cutouts were located 1.27 centimeters from the mounting plate. EDO Corporation Model E200P-5 actuators were selected based on force and stroke capabilities as well as their low price and ready availability. These actuators operate in a -20 to $400 \mathrm{~V}$ range, have a sensitivity of $0.048 \mu \mathrm{m} / \mathrm{volt}$, and a stiffness of $100 \mathrm{~N} / \mu \mathrm{m}$. A 20 volt DC bias applied to the actuators minimizes the possibility of their exposure to potentially harmful tensile loads.

A force transducer was located in series with the actuators to monitor control force inputs. Also, a three axis Endevco accelerometer was placed at the bar tip and a Micro-Measurements strain gage was placed near the bar root.The assembled bar exhibited good separation between the first and second bending modes in the $x-y$ plane at approximately 214 and 885 Hertz which include the stiffening effects of the actuators. 


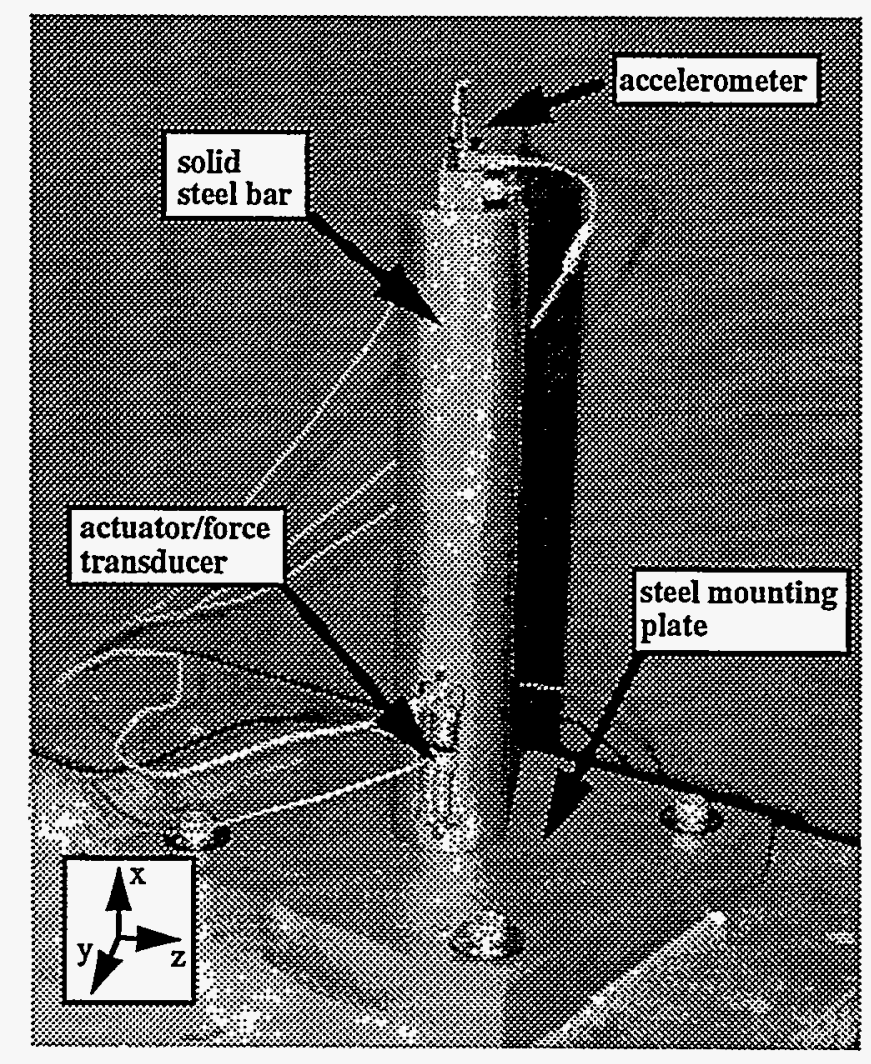

Figure (5): Test setup for bar damping experiment.

Tip acceleration, root strain, and transducer force signals were monitored and each were investigated as feedback signals. The feedback signal was fed into a Microstar DAP3200 board utilizing an on-board 486 based $100 \mathrm{MHz}$ processor. Voltage outputs were augmented by Kron Hite amplifiers before being applied to the actuators. The accelerometer proved to be the most reliable measurement of the low amplitude vibrations due to its higher signal to noise ratio.

A positive position feedback (PPF) (Fanson and Caughey,1990) filter, described later, with a natural frequency of $214 \mathrm{~Hz}$ and a damping ratio of 0.3 was used to augment the damping in the first mode. Tip impact tests on the open and closed-loop systems were conducted to judge the effectiveness of the control scheme in damping the first mode. Frequency response functions relating tip force to tip acceleration were determined by averaging 5 impact tests. Evidence of the ability of the control system to damp the first mode without affecting the higher modes is provided by the magnitude of the frequency response function. As shown in Figure 6, a $20 \mathrm{db}$ reduction in first mode amplitude was achieved with minor differences between the open and closed-loop curves evident throughout the remainder of the frequency range shown. First mode damping increased from an estimated $0.8 \%$ to $5.2 \%$ of critical as a consequence of the control system.

\section{MULLING SIMULATION RESULTS}

To demonstrate the potential of damping a single mode to improve the performance of a milling machine, models of the open and closed loop systems from the bar damping experiment were incorporated into the milling simulation described in the previous section. The single axis transfer functions measured in the experiment were assumed to be representative of the dynamics of a milling tool in both the infeed and cross feed directions. Note, as indicated in the 


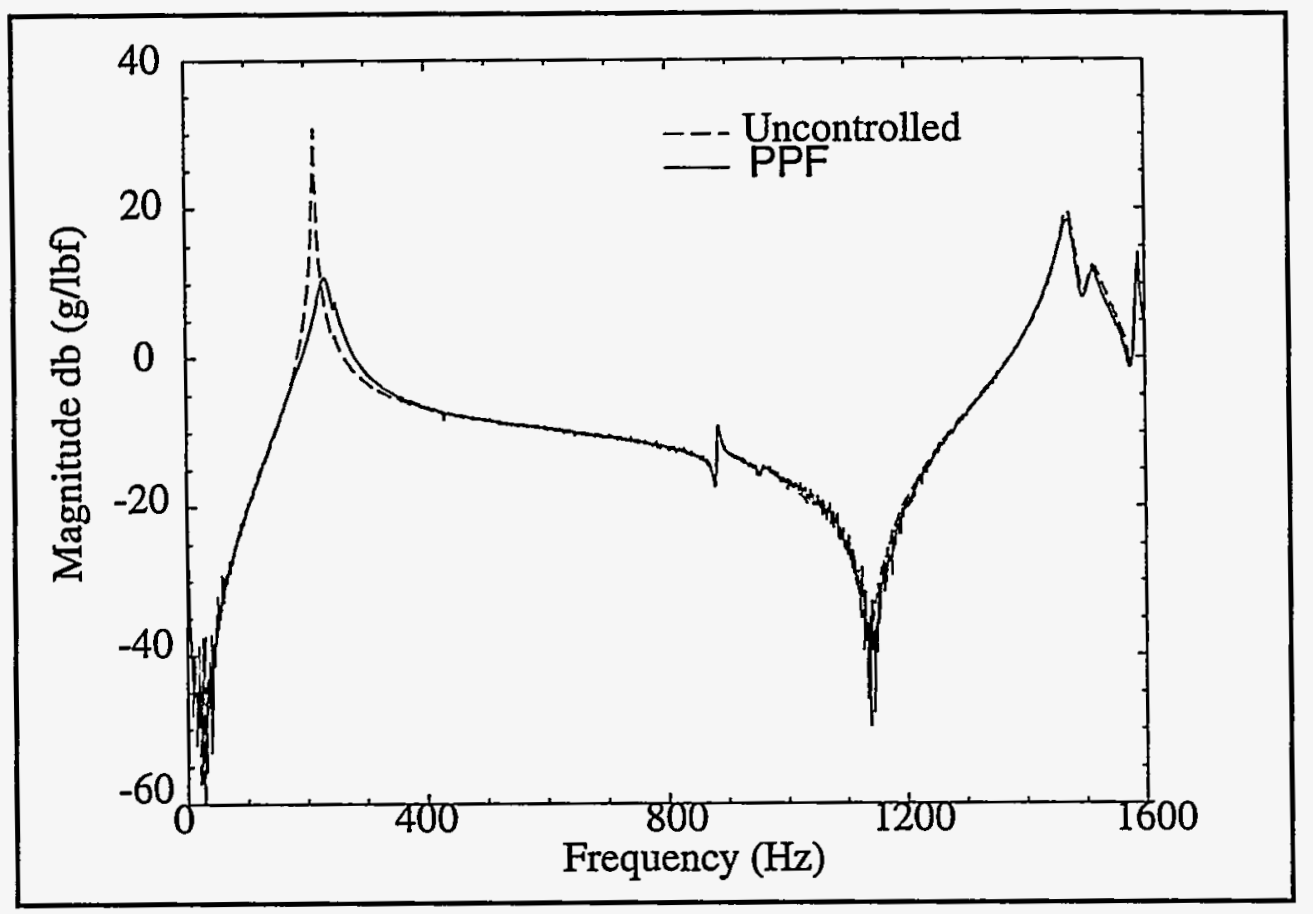

Figure (6): Magnitude of tip force to tip acceleration transfer function.

prior section, the dynamics of the milling machine's spindle and tool could also be approximated by a finite element model if the hardware didn't exist. With a constant chip loading of $0.1 \mathrm{~mm}$ (maximum nominal chip thickness) on a $20 \mathrm{~mm}$ diameter cutting tool with four teeth, slotting cuts in aluminum were simulated over a broad range of process parameters.

Vibration amplitude contours for the open and closed loop cases are shown in Figure 7 and Figure 8 for tool speeds ranging from 2000 to $5000 \mathrm{rpm}$ and the depth of cut ranging from 0.01 to $2 \mathrm{~mm}$. The vibration amplitudes were taken after 10 rotations of the cutting tool. Although this duration is not sufficient to achieve steady state cutting in all cases, the amplitude after 10

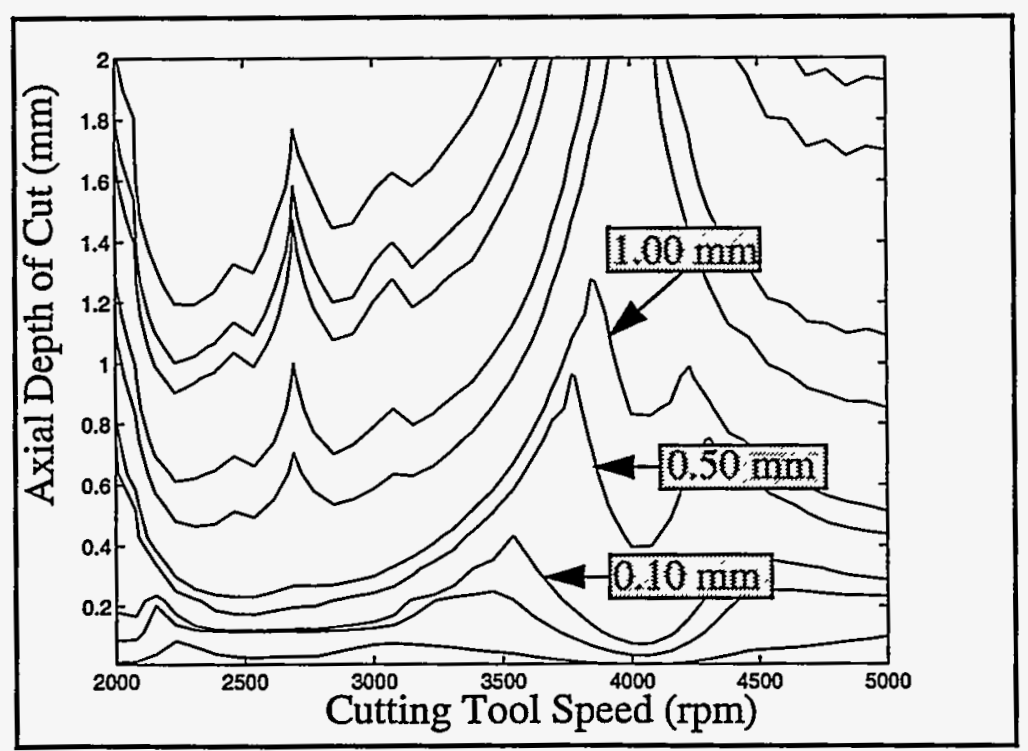

Figure (7): Simulated peak to peak tool vibration amplitude contours for open loop bar syster 


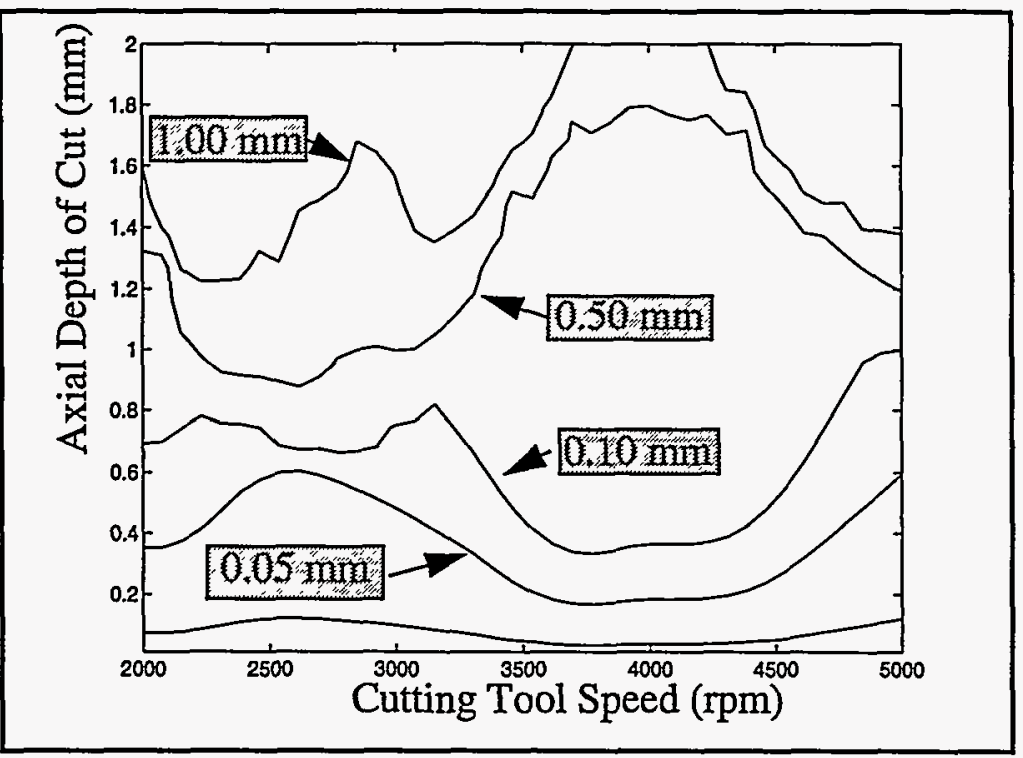

Figure (8): Simulated peak to peak tool vibration amplitude contours for closed loop bar syster revolutions is sufficient for determining the relative stability of each set of cutting conditions. The open loop case, shown in Figure 7, clearly exhibits the classical lobing structure of the stability curves, but relatively high levels of vibration are encountered for low depths of cut. In fact, the low dynamic stiffness of this cutting tool led to unbounded growth of the tool chatter for many conditions simulated. This phenomenon is a remnant of the assumption of linearity in the relationship of cutting forces to instantaneous depth of cut (Tlusty and Ismail, 1983). The closed loop case in Figure 8 indicates that a significant reduction in tool vibration amplitude is achieved as compared to the open loop case. For example, with a tool speed of $3000 \mathrm{rpm}$ and a depth of cut of $0.4 \mathrm{~mm}$, the closed loop case exhibits less than $0.05 \mathrm{~mm}$ of peak to peak vibration as compared to greater than $1 \mathrm{~mm}$ for the uncontrolled case. The lobing structure of the stability diagram for the closed loop case is best illustrated through a three dimensional stability surface displayed in Figure 9. Note that highly stable cutting conditions exist for tool speeds in the neighborhood of $4000 \mathrm{rpm}$. At this speed, the tooth passing frequency coincides with the frequency of the first bending mode of the cutting tool. This stability condition has been the subject of much recent research and has been exploited for the development of an automated chatter avoidance system (Smith and Delio,1992).

To further illustrate the effect of the active damping, the tool vibration relative to the nominal infeed is shown in Figure 10 and Figure 11 for a cutting speed of $3000 \mathrm{rpm}$ and a depth of cut of $0.25 \mathrm{~mm}$. For the open-loop case, the chatter vibration amplitude quickly exceeds the nominal chip loading and appears to stabilize at around $0.7 \mathrm{~mm}$ peak to peak. Conversely, after an initial transient associated with the gradual engagement of the tool and the workpiece, the vibration of the closed loop case quickly dissipates. The $0.001 \mathrm{~mm}$ static deflection of the cutting tool is a consequence of the DC component of the axial cutting force.

\section{FINITE ELEMENT MODELING OF A PHOTOLITHOGRAPHY PLATEN}

This section presents a conceptual design (Redmond et al., 1994) of a supplemental flexible body control system for a magnetically levitated platen used in the manufacture of integrated circuits. Recently, a two stage positioning system which combines large travel capabilities and precision placement capabilities was developed for use in photolithography-based IC 


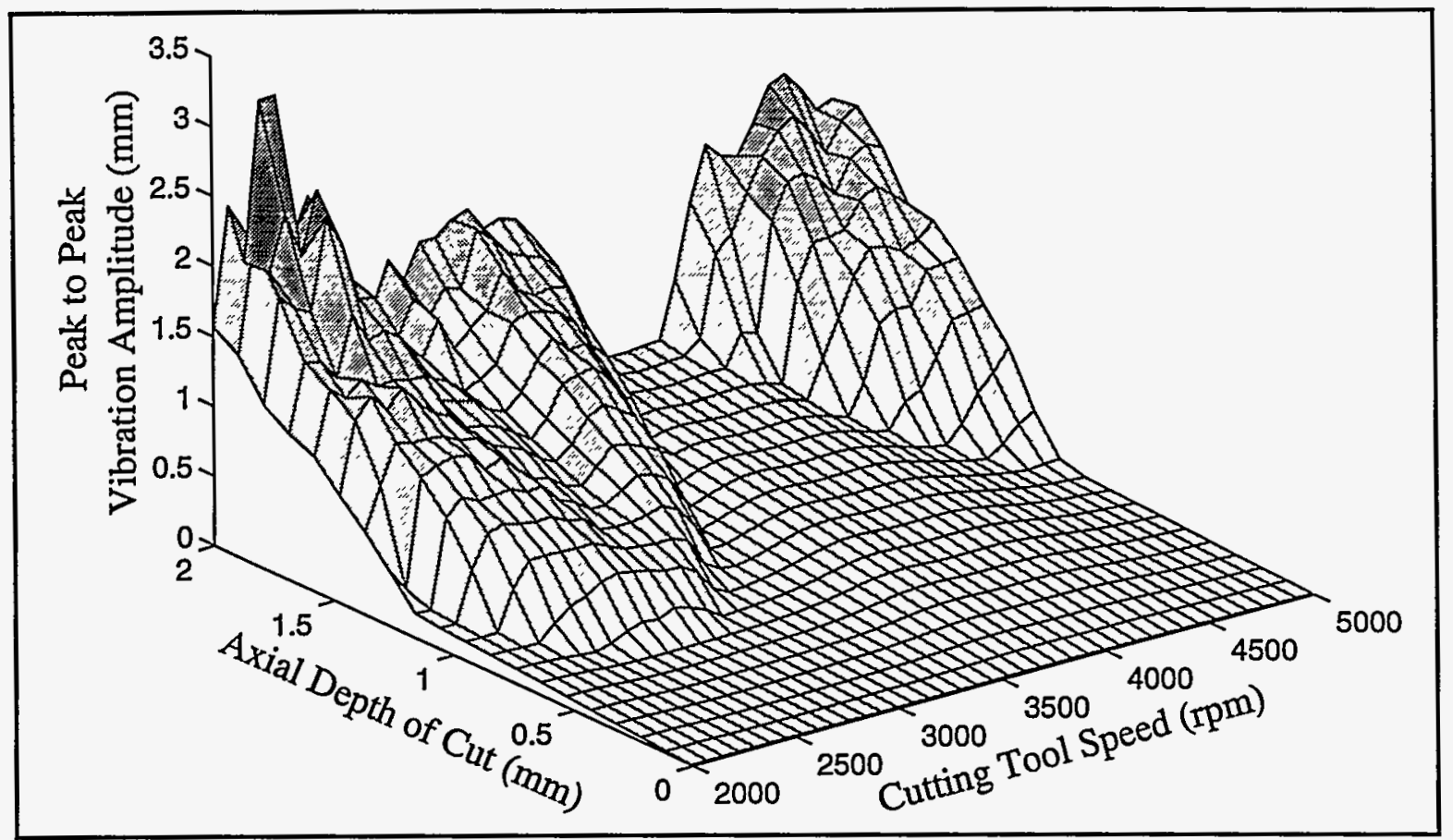

Figure (9): Simulated stability surface for the closed loop bar system.

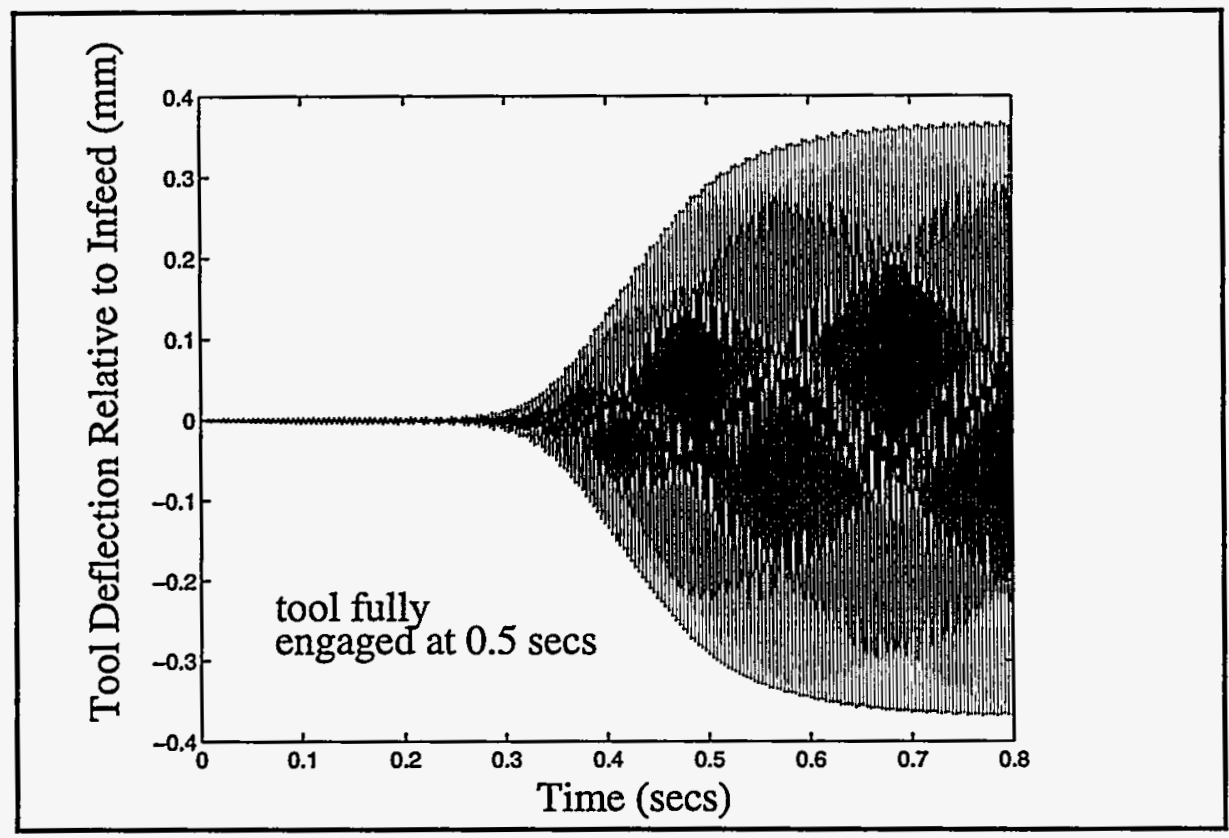

Figure (10): Tool deflection relative to infeed for open loop system with $3000 \mathrm{rpm}$ tool speed and $0.25 \mathrm{~mm}$ axial depth of cut.

manufacturing (Arling and Kohler, 1993). In this system, a coarse stage drives a fine stage through large travel distances (up to $200 \mathrm{~mm}$ ) using motor driven ball screws. The platen is magnetically levitated within the coarse stage frame which contains the actuation hardware. The required travel for the fine stage depends on the accuracy of the coarse stage. Typical maneuvers are in the $+/-30 \mu \mathrm{m}$ range. Since the platen is magnetically levitated, positioning limitations caused by friction, machining tolerance, and hysteresis are virtually eliminated. In recent tests, this two stage system consistently produced placement accuracies better than $10 \mathrm{~nm}$. However, 


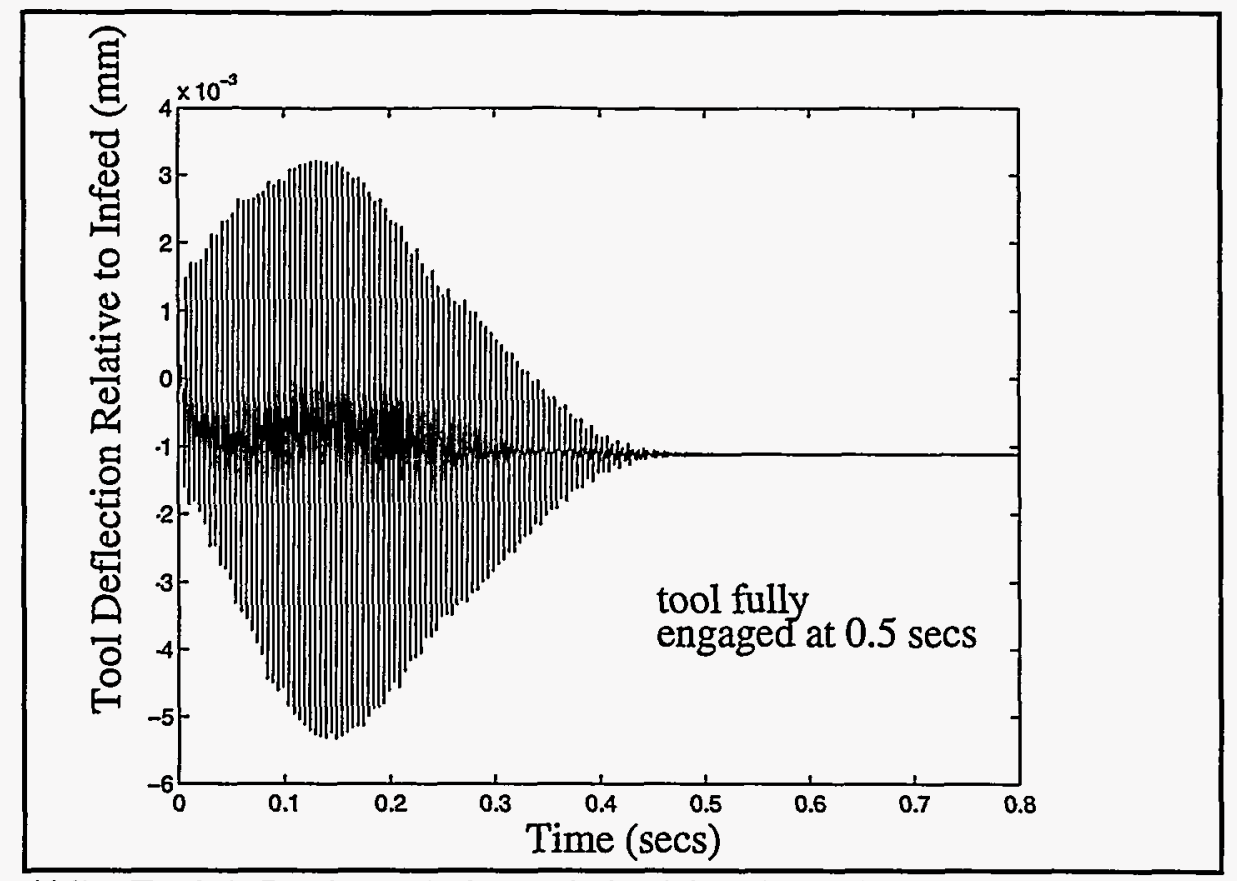

Figure (11): Tool deflection relative to infeed for closed loop system with $3000 \mathrm{rpm}$ tool speed and $0.25 \mathrm{~mm}$ axial depth of cut.

as with many positioning systems, excitation of flexible body modes limits the positioning speed. To address this problem, a new platen was designed to incorporate active structural control technology.

Much recent research has focused on the use of imbedded or surface mounted piezoelectric actuators for control of plate-like structures. In particular, active buckling (Chandrashekhara and Bhatia, 1993) and shape control (Koconis, Kollar and Springer, 1994a; 1994b) have been considered. The application of piezoelectric devices to active vibration control of plates has focused on relatively low frequency modes afforded by thin plates (Tanaka, Kikushima and Kuroda, 1992). To control the high frequency vibrations of the relatively thick photolithography platen, we consider the use of flush mounted (PZT) stack actuators.

\section{LOCATING ACTUATORS}

Proper placement of the PZT actuators requires attention to both location and orientation. Each actuator should be placed in a region of high curvature along the direction of peak normal strain. Preliminary actuator locations are selected by examination of the strain contours of each mode below the $2 \mathrm{kHz}$ threshold. A finite element model of the platen was developed which predicted the first five natural frequencies to be $972,1619,1782,2685$ and $2855 \mathrm{~Hz}$ respectively. The first and second mode shapes with their strain energy density contours are shown in Figure 12. Several rest to rest maneuvers of the platen were simulated with the finite element model and root-mean-square (rms) strain levels were computed at several candidate actuator locations. The actuator positions which had the highest rms strain levels for the simulated maneuvers were chosen as the final locations and are shown in Figure 13. 


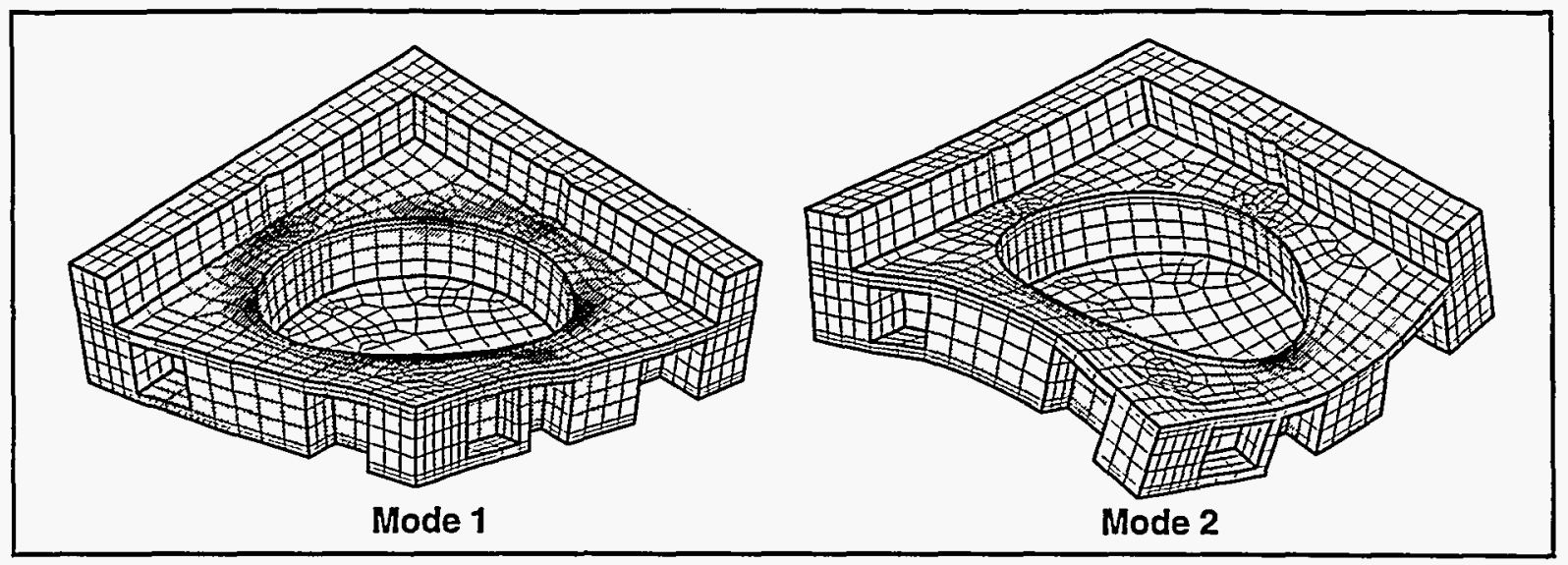

Figure (12): First and second flexible mode shapes of a lithography platen/mirror.

\section{EXPERIMENTAL RESULTS ON CONTROLLING THE PLATEN}

Based on the above actuator placement and location analysis, actuator mounting pockets were included in the final platen design and two platens were subsequently machined from aluminum blocks. The first platen was earmarked for integration into the magnetically-levitated system, and includes the mirrored surfaces necessary for laser-based rigid body positioning. The second, or surrogate, platen serves as a vehicle for checking out many of the novel features of the active vibration control system prior to implementation on the magnetically-levitated platen. As such, an exact match between the dynamic characteristics of the two platens is not necessary, and many steps were omitted during the fabrication of the surrogate platen to save time and money. However, only steps believed to have a minimal impact on the platen's dynamic characteristics were eliminated, and the surrogate platen includes all material cutouts featured in the magnetically-levitated platen.

The surrogate platen fitted with sensors and actuators is shown in Figure 13 resting on a styrofoam base to simulate free-free boundary conditions. The three Physik Instrumente Model 840.1 actuators are mechanically pre-loaded into the specially designed mounting pockets. In addition a 20 Volt $\mathrm{DC}$ bias is applied to the actuators to minimize the possibility of pre-load loss as a result of large platen deformations. A close up of an actuator assembly is shown in Figure 14. Applying a voltage across the actuator produces an internal strain, resulting in equal and opposite forces being applied to the platen at the interfaces. Note that since the actuators are mounted near the platen surface, the actuator forces induce equal and opposite bending moments in the platen. Modal control authority stems from the difference in the spatial derivatives of the mode shapes evaluated at the actuator-platen interfaces. A simplified explanation of this interaction is detailed in (Redmond et al., 1995) for a cantilevered bar.

The dynamic response of the platen in bending is influenced by the presence of the three actuators in both a passive and an active sense. Neglecting actuator hysteresis and the voltage induced by actuator deformation, the total actuator force is given by

$$
F(t)=K_{a}(\eta V(t)-\Delta L(t))
$$




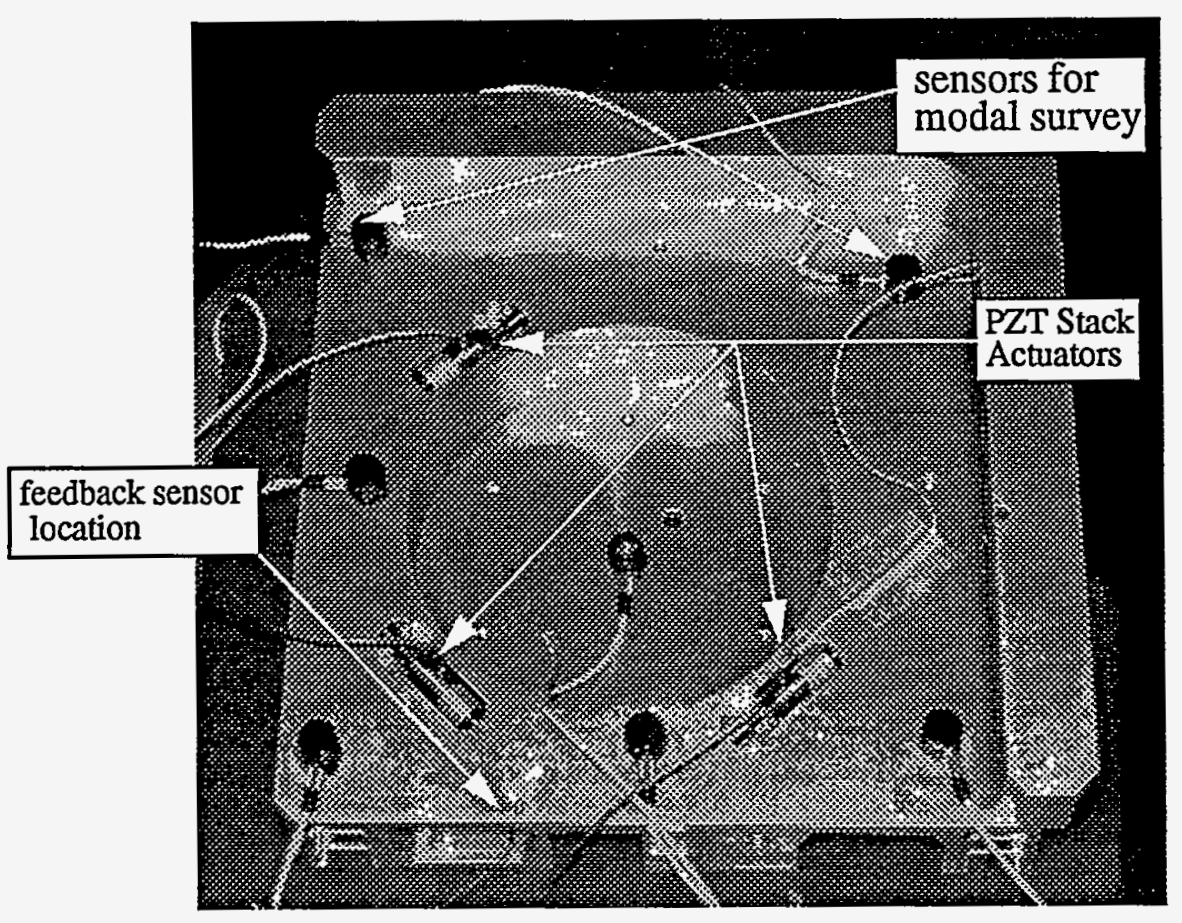

Figure (13): Surrogate platen fitted with accelerometers and PZT actuators.

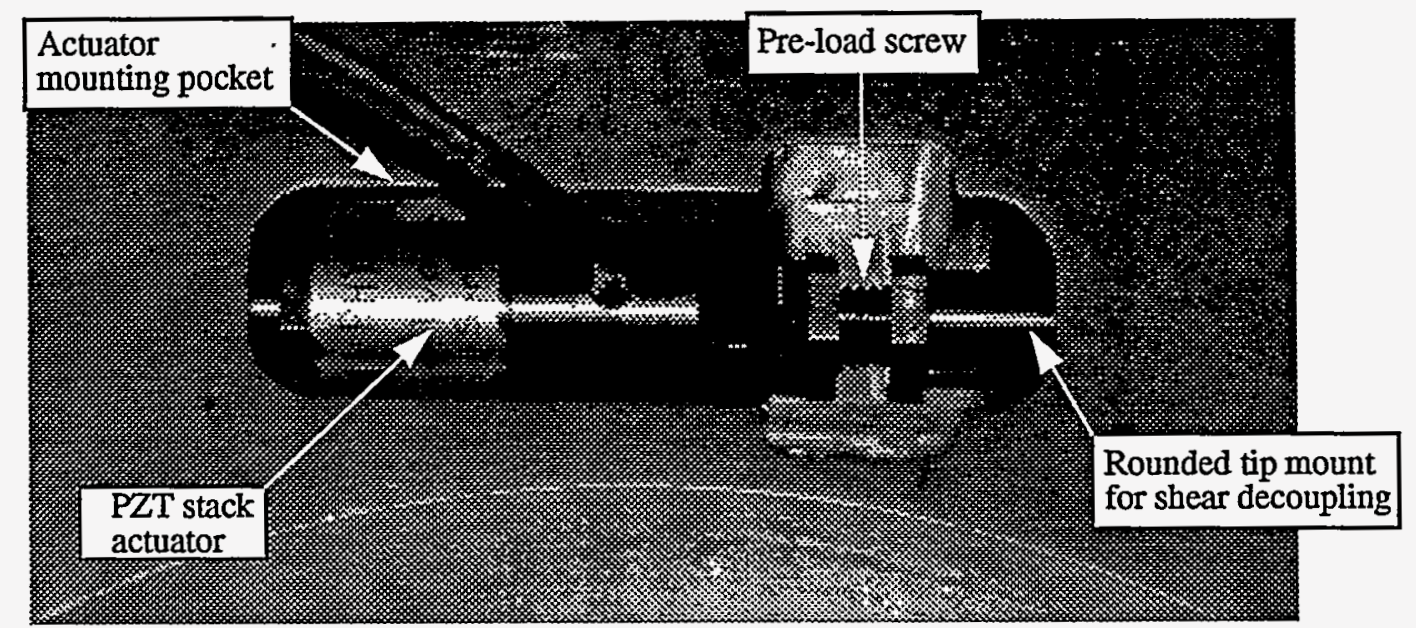

Figure (14): Physik Instrumente Model 840.1 actuator mounted in platen.

in which $K_{a}$ represents the actuator stiffness, $\eta$ is the actuator's piezoelectric constant, $V(t)$ is the input voltage, and $\Delta L(t)$ is the axial elastic deformation of the actuator resulting from the platen deformation. The elasticity of the actuators provides a small but beneficial stiffening effect that partially compensates for the decreased stiffness resulting from the existence of the mounting pockets. The induced strain component of the force includes both a DC component for actuator pre-load and a frequency dependent component for control.

\section{CONTROL DESIGN}

A block diagram of the experimental system is shown in Figure 15. For simplicity, the elastic and DC voltage components of the actuator force have been absorbed in the plant transfer 
function $G(s)$. The system is subjected to a disturbance force which for this experiment takes the form of a hammer impulse. The objective of this experiment is to augment the damping in the first two modes without causing instability in the higher frequency modes. The Positive Position Feedback (PPF) control strategy provides a useful approach for targeting specific vibrational modes through active control (Fanson and Caughey, 1990). Collocation of the sensors and actuators is a basic assumption of this approach and guarantees that all control spillover is stabilizing even in the presence of finite actuator bandwidth. A displacement-like measurement collocated with the actuator is fed through a compensator $K(s)$ to produce actuator excitation voltages. Appropriate feedback signals include measurements such as strain that are in phase with actuator displacement. Acceleration measurements can be used, as is the case in this experiment, if the 180 degree phase shift is accommodated. In addition, noncollocation of the sensor and actuator can be handled for a specific mode by accounting for the phase difference between the actuator and sensor locations. However, robustness to control spillover is no longer guaranteed since a non-minimum phase zero is introduced.

Assuming second order dynamics, the general form of the compensator is given as

$$
K(s)=\frac{g \omega_{f}^{2}}{s^{2}+2 \zeta_{f} \omega_{f} s+\omega_{f}^{2}}
$$

The filter poles are placed in the s-plane to effect a desired migration of the closed loop system poles as the compensator gain is increased. Typically, each local feedback loop is used to target a single mode, but multiple modes can be targeted through judicious placement of the compensator poles.

To illustrate the concept of PPF, we consider acceleration feedback using a model of the surrogate platen that includes the first three vibrational modes extracted from a modal survey of the surrogate platen (Barney, 1995). The model frequency response function is shown in Figure 16. Modes are clearly evident at 1052 and $1625 \mathrm{~Hz}$. Note that these frequencies differ from those obtained from the finite element model which did not account for the material removed as required to accommodate the PZT actuators. In an effort to augment the damping of the first mode, the compensator is assigned an undamped natural frequency of $1 \mathrm{kHz}$ and a damping ratio of 0.5 . The root locus for this feedback system is shown in Figure 17. As the gain is

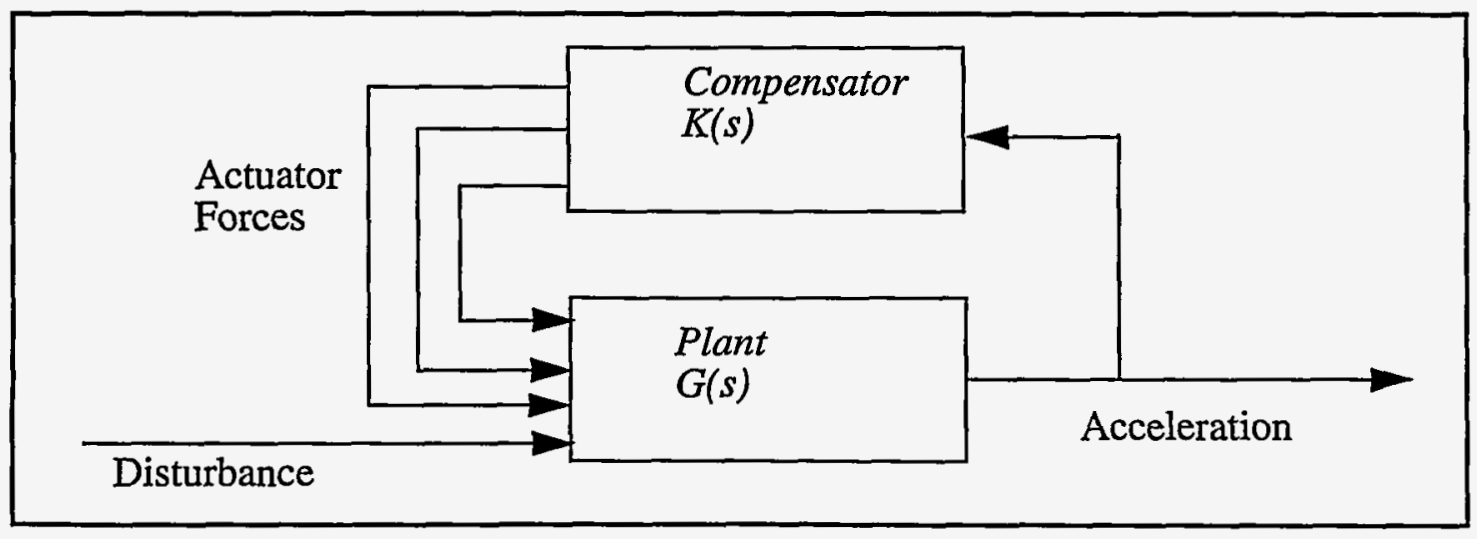

Figure (15): Block diagram of closed loop system with acceleration feedback. 

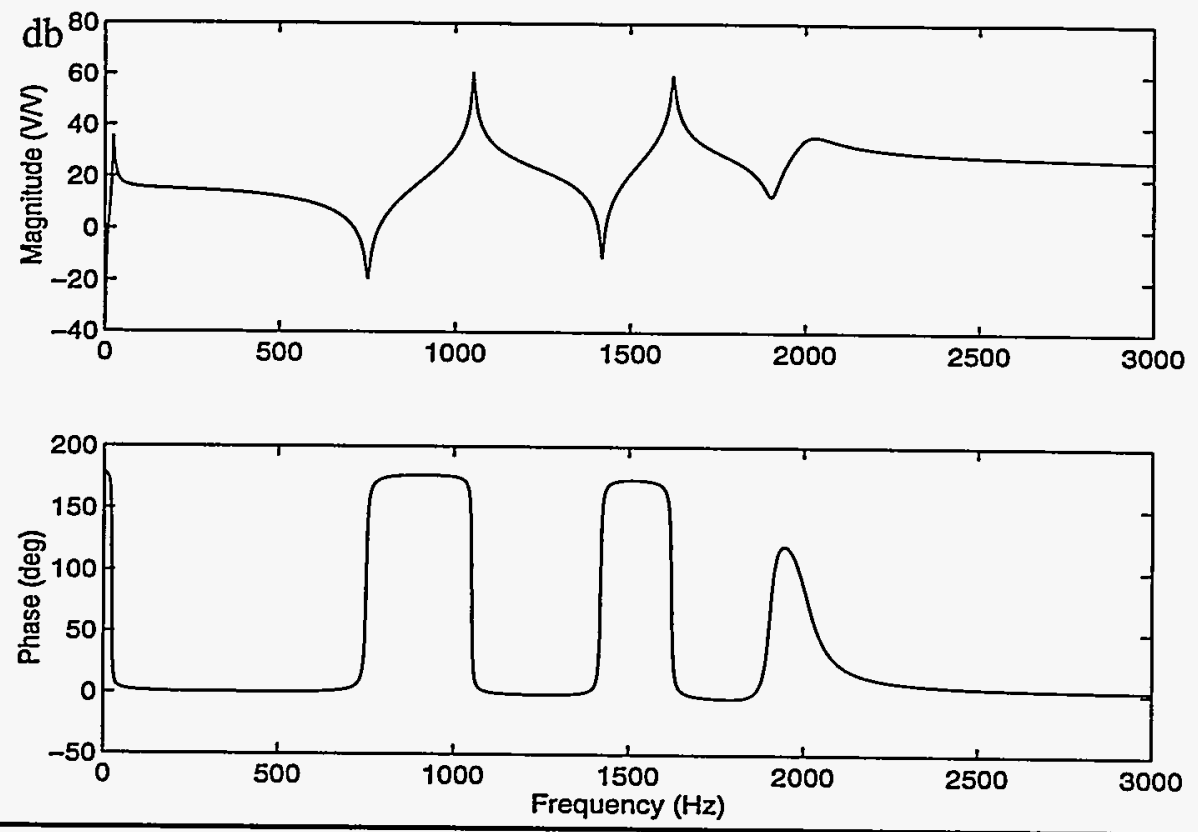

Figure (16): Model of frequency response function from impact hammer to accelerometer.

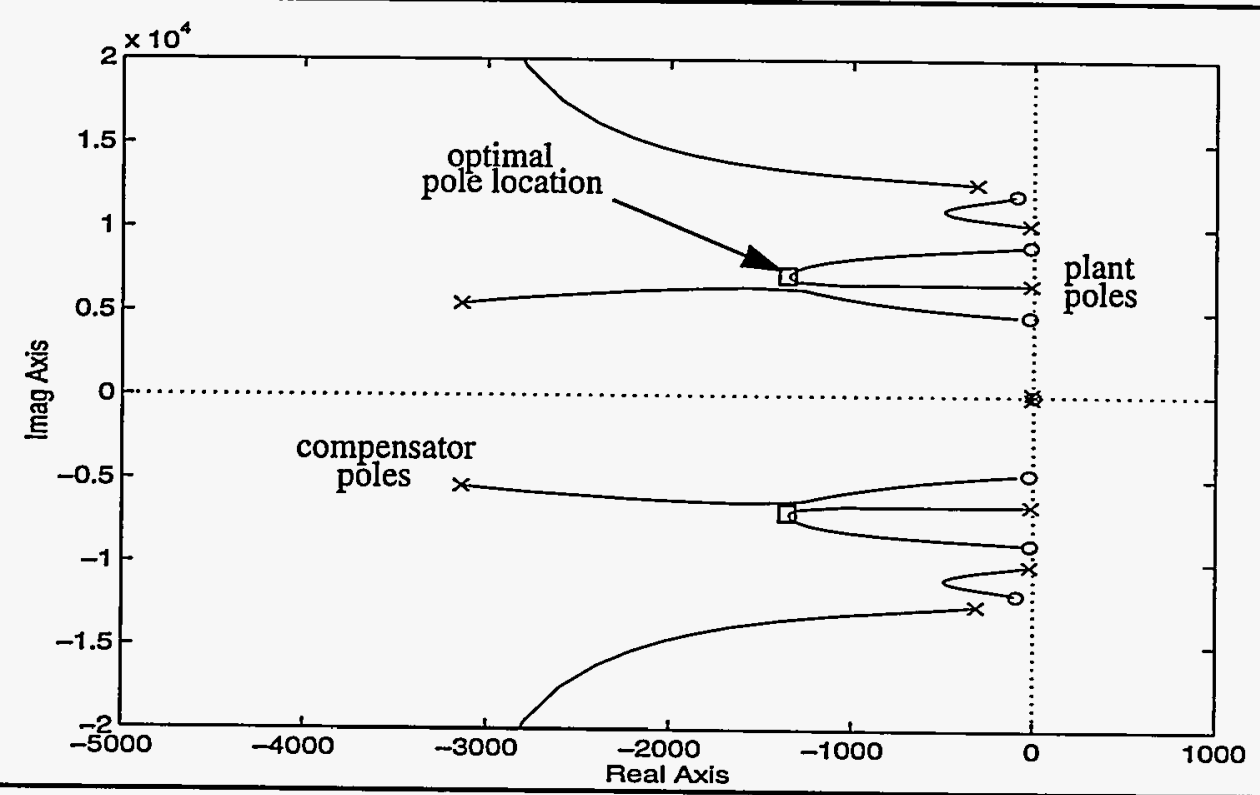

Figure (17): Root locus for acceleration feedback with second order compensator.

increased, the compensator poles migrate toward the zeros of the open loop plant occurring near $750 \mathrm{~Hz}$. This migration effects a drift of the first mode poles into the left half plane prior to migrating toward the open loop zero near $1440 \mathrm{~Hz}$. The optimal gain for this compensator is that which places the first mode poles in the box indicated. Note that the acceleration feedback places two zeros at the origin which attract the rigid body mode included near $100 \mathrm{~Hz}$.

\section{EXPERIMENTAL RESULTS}

After much experimentation with a variety of sensors, an accelerometer mounted near the location of maximum displacement for mode 1 (as indicated in Figure 13) was selected for the 


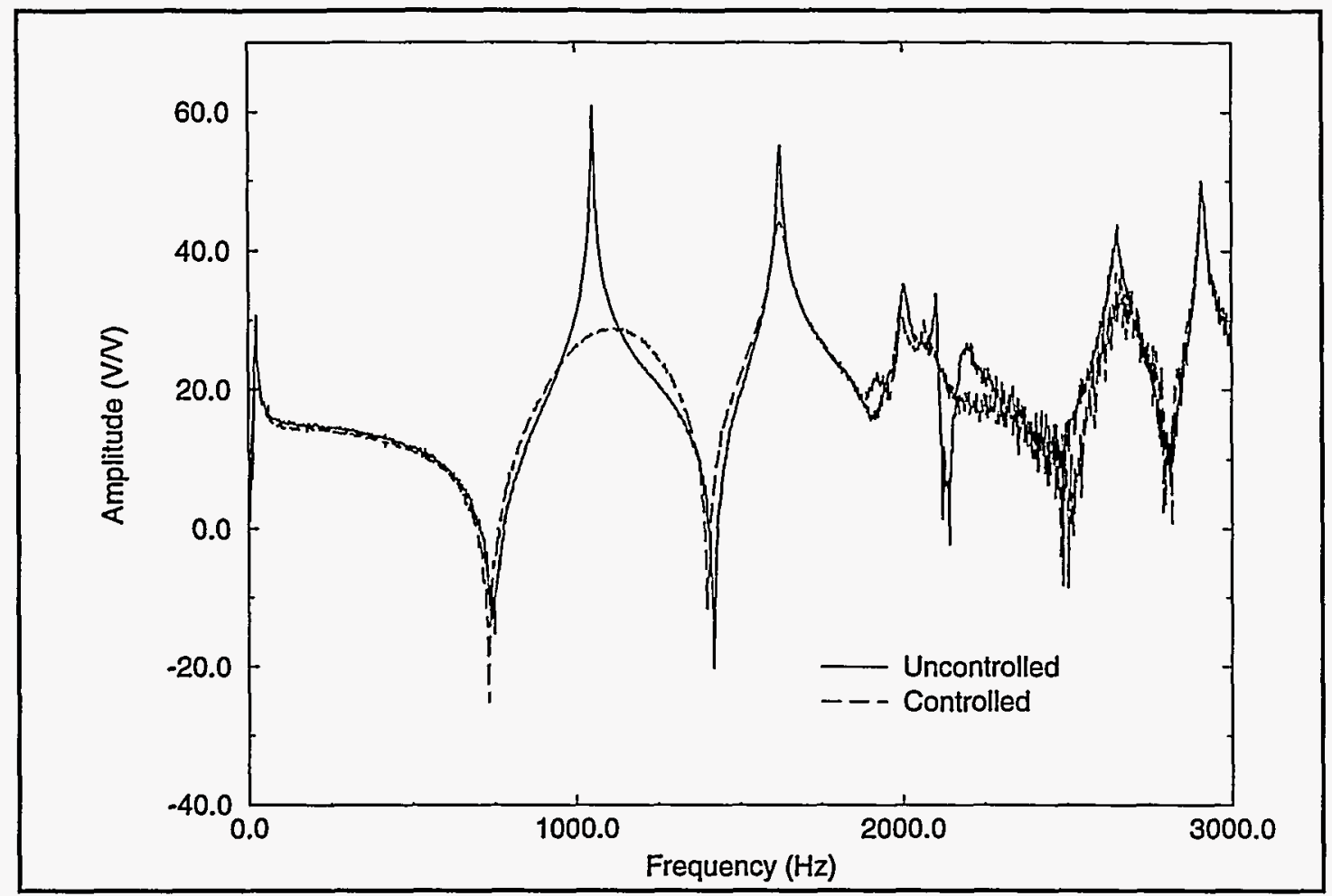

Figure (18): Open and closed loop transfer function magnitude.

feedback signal. The objective of the experiment was to actively augment the damping in the first two vibrational modes. The acceleration signals were passed through a linear phase low pass filter with a break frequency of $4 \mathrm{kHz}$ prior to being sampled by the dSpace controller operating at 17,000 samples per second. A similar smoothing filter was placed at the output of the controller and helped to eliminate earlier problems associated with intermittent pre-load loss at the actuator-platen interface.

The best results for damping modes 1 and 2 were obtained using a second order filter with the undamped natural frequency set to $1236 \mathrm{~Hz}$ and a damping ratio of 0.5 . Each actuator was tested independently to determine the proper polarity of the drive voltage needed in light of the chosen sensor location. The individual feedback gains were set manually in an effort to maximize damping without exceeding the actuator drive voltages. Averaged frequency response functions from impact excitation to the accelerometer are given in Figure 18 for both the open and closed looped cases. A peak reduction in mode 1 of $32 \mathrm{db}$ is achieved for this case with a simultaneous reduction of $11 \mathrm{db}$ in mode 2 . Only minor differences are visible in the magnitudes of the higher modes.

\section{CONCLUDING REMARKS}

Results, given in this paper, demonstrate the potential benefit that can be realized by applying advances from the field of adaptive structures to problems in precision manufacturing. Detailed finite element modeling and simulated modal analyses of the spindle/tool assembly of a milling machine and photolithography platen were shown. The milling machine finite element analysis identified potentially unobservable modes of vibration that could contribute to cutting tool displacements. It also identified promising control strategies to avoid these modes and 
minimize cutting tool displacements. The platen finite element model was used in simulation studies to determine optimal actuator locations for the hardware experiments.

The milling process was simulated based on an existing cutting force model and an experimentally derived model of a surrogate milling machine's structural dynamics. Results of this simulation indicate that the stability of the cutting process can be significantly improved using a positive position feedback vibration control scheme. A factor of 10-200 reduction in tool vibration amplitudes was realized over a wide range of cutting conditions. Application to turning and boring machines can be realized with only modest adjustments to the demonstration system. However, the proposed actuation method requires the inclusion of actuator mounting pockets in the host tool, compromising the tool's static stiffness which governs its ability to hold tight tolerances. Improved methods for incorporating smart material actuators in cutting tools without a significant decrease in static stiffness are needed. Furthermore, details related to sensing and actuation of high speed rotating equipment must be addressed before this technique can be implemented on a milling machine.

Along with the bar experiments, the damping experiments conducted on the surrogate platen have provided many valuable lessons concerning the implementation of the proposed magnetically-levitated platen vibration control strategy. In particular, actuator mounting, preload, and excitation guidelines have been established to produce significant vibrational control authority without inducing harmful bending stresses in the fragile actuators. Furthermore, preliminary tests on the surrogate platen have demonstrated the capabilities of the active vibration control system to effectively damp the platen modes. Using a low order controller, the damping in the first mode was increased from $0.2 \%$ to $12.0 \%$ of critical while the second mode damping increased from $0.2 \%$ to $2 \%$ critical. Further controller development is being reserved for the mag-lev system which is nearing completion.

\section{ACKNOWLEDGMENTS}

This work performed at Sandia National Laboratories is supported by the U.S. Department of Energy under contract DE-AC04-94AL85000. The authors appreciate the assistance of Jeffrey Dohner, Garth Reese, Gordon Parker, Patrick Barney who are all senior members of the technical staff at Sandia National Laboratories. We also appreciate Gordon Cook and the EDO corporation for providing the PZT actuators for the bar experiment.

\section{REFERENCES:}

Arling, R. W., and S. M. Kohler. 1993. "Six Degree of Freedom Fine Motion Positioning Stage Based on Magnetic Levitation," NASA Conference on Magnetic Leviation.

Barney, P.S. 1995."Platen Quick Modal Results," Sandia National Laboratories Technical Memorandum, Dept. 2741.

Chandrashekhara, K. and K. Bhatia. 1993. "Active Buckling Control of Smart Composite Plates-Finite Element Analysis," Smart Materials and Structures, 2(1):31-39.

Dohner, J.L. 1995. “Actuator, Sensor, and Spindle Design," Sandia National Laboratories Technical Memorandum, Dept. 1434.

Dohner, J.L. 1994. "The Eigensystem Realization Algorithm and the Eigensystem REalization Algorithm with Data Correlation: Theory and Application," Sandia National Laboratories Technical Memorandum, Dept. 1434.

Fanson, J.L. and T. K. Caughey. 1990. "Positive Position Feedback Control for Large Space Structures," AIAA 
Journal, Vol. 28, No. 4, pp. 717-724.

Jemielniak, K. and A. Widota. 1989. "Numerical Simulation of Non-Linear Chatter Vibration in Turning," International Journal of Machine Tools Manufacturing, Vol. 29, No. 2, pp. 239-247.

Juang, J. N., and R. S. Pappa. 1985. “An Eigensystem Realization Algorithm for Modal Parameter Identification and Model Reduction," Journal of Guidance, Vol. 8, No. 5, pp. 620-627.

Koconis, D. B., Kollar, L. P., and G. S. Springer. 1994a. "Shape Control of Composite Plates and Shells with Embedded Actuators. I. Voltages Specified," Journal of Composite Materials, 28(5):415-458.

Koconis, D. B., Kollar, L. P., and G. S. Springer. 1994b. "Shape Control of Composite Plates and Shells with Embedded Actuators. II. Desired Shape Specified," Journal of Composite Materials, 28(5):459-482.

Manufacturing Laboratories, Inc., Gainsville, FL. 1993. "High Speed High Power Machining," seminar notes.

Redmond, J.M., Parker, G.G., Barney, P.S., and R. Rodeman. 1995. "Active Control of Bending Vibrations in Thick Bars Using PZT Stack Actuators," to be presented at the 1995 ASME International Congress and Exposition, November 13-17.

Redmond, J.M., and J. L. Dohner. 1994. "Vibration Suppression of the Photolithography Platen Mirror Using Voice Coil Actuators," Sandia Internal Memorandum, Dept. 1434.

Redmond, J. M. 1994. "Modeling/Simulation for Vibration control of High Speed Milling Machines," Sandia National Laboratories Technical Memorandum, Dept. 1434.

Redmond, J. M. 1995. “Simulated Milling Stability enhancements Through Active Damping," Sandia National Laboratories Technical Memorandum, Dept. 1434.

Redmond, J. M., J.L. Dohner, G.G. Parker, G.M. Reese. 1994. "Segregated Rigid and Flexible Body Controls for a Photolithography Positioning System", presented at the Fifth International Conference on Adaptive Structures, Sendai, Japan.

Smith, S. and J. Tlusty. 1987. "Update on High-Speed Milling Dynamics," Symposium on Integrated Intelligent Manufacturing Analysis and Synthesis, PED Vol. 25, pp. 153-165.

Smith, S. and J. Tlusty. 1988. "NC Programming for Quality in Milling," 16th NAMRC, pp. 279-286.

Smith, S. and J. Tlusty. 1991. "An Overview of Modeling and Simulation of the Milling Process," Journal of Engineering for Industry, Vol. 113, pp. 169-175.

Smith, S. and T. Delio. 1992. "Sensor-Based Chatter Detection and Avoidance by Spindle Speed Variation," Journal of Dynamic Systems, Measurement, and Control, Vol. 114, pp. 486-492.

Tanaka, N. Y., Kikushima, and M. Kuroda. 1992. "Power Flow Control of a Thin Plate," First International Conference on Motion and Vibration Control, Yokohama, Japan:56-61.

Tarng, Y. S. and T. C. Li. 1994. "Detection and Suppression of Drilling Chatter," Journal of Dynamic Systems, Measurement and Control, Vol. 116, pp.729-733.

Tlusty, J. and F. Ismail. 1983. "Special Aspects of Chatter in Milling," Journal of Vibration, Acoustics, Stress, and Reliability in Design, Vol. 105, pp. 24-32. 


\section{BIOGRAPHY FOR: David R. Martinez}

EDUCATION: BS Mechanical Engineering, University of New Mexico, 1965-1969

MS Applied Mechanics, Cal Tech, 1969-1970

Ph. D. Mechanics and Structures, UCLA, 1977-1979

\section{WORK EXPERIENCE: Sandia National Laboratories, 1969 - present}

David has performed research in various areas of structural dynamics and system identification. $\mathrm{He}$ developed coupled analytical/experimental dynamic substructuring methods for structural systems. He developed Kalman Filtering and Bayesian estimation techniques for parameter identification in finite element models.

Since 1988, David has been the Manager of the Structural Dynamics and Vibration Control Department at Sandia National Laboratories. The Department consists of 20 professional staff members (80\% Ph.D., 20\% MS) and is an Engineering Science discipline in the Computational Sciences, Computer Sciences, and Mathematics Center at Sandia. The group performs R\&D in support of defense and industrial projects, including manufacturing, energy, and technology transfer programs. Most activities involve modeling of systems and structures using finite element, boundary element, and other numerical simulation techniques. Multidisciplinary R\&D and analyses are performed in structural dynamics, structural control and vibration suppression, system identification, integrated analytical/experimental model verification \& simulation, smart material systems and adaptive structures, flexible robotics, dynamics of rotating structures, structural damping, and optimization techniques. The activities of his department plus those of the Smart Structures and Materials Lab involve approximately 35 technical staff.

David is actively involved in the organization of various conferences in the field of Adaptive Structures and Intelligent Material Systems.

\section{BIOGRAPHY FOR: Terry D. Hinnerichs}

EDUCATION: BS Mechanical Engineering, University of Nebraska, 1969

MS Mechanical Engineering, Colorado State University, 1973

$\mathrm{Ph}$. D. Aeronautical Engineering, U.S. Air Force Institute of Technology, 1980

\section{WORK EXPERIENCE:}

Terry has completed a 20 year career in the Air Force as a R\&D mechanical engineer which involved analytical and experimental projects in fracture mechanics, structural dynamics, blast and shock loading of protective structures, active and passive vibration control and isolation of precision structures, constitutive modeling for high temperature metals and geomaterials. His dissertation was on finite element modeling of creep crack growth in jet engine turbine disks. Taught graduate engineering courses in structural analysis, experimental mechanics and mechanical measurements as a faculty member at the Air Force Institute of Technology. Currently, he is an Amparo Corp. employee on contract to the Structural Dynamics and Vibration Control Department at Sandia National Laboratories as a senior mechanical engineer performing linear and nonlinear structural analyses and the application of smart materials to weapon systems and precision manufacturing machines.

\section{BIOGRAPHY FOR: James M. Redmond}

EDUCATION: BS Aerospace Engineering, North Carolina State University, 1987

MS Aerospace Engineering, North Carolina State University, 1989

Ph. D. Mechanical Engineering, North Carolina State University, 1992

\section{WORK EXPERIENCE:}

Jim's graduate work had an emphasis on optimal control of flexible spacecraft. After a post-doc at North Carolina A\&T State University working on dynamic characterization of braided and woven composites, Jim joined the staff at Sandia National Laboratories. Currently, he is a Senior Member of the Technical Staff in the Structural Dynamics and Vibration Control Department. His primary research focus is the application of smart materials for vibration suppression of precision manufacturing machines. 